\title{
PELATIHAN KEARSIPAN BAGI GURU DAN TENAGA KEPENDIDIKAN DI DAYAH DARUL IHSAN ACEH BESAR
}

\author{
Zahriatul Aini ${ }^{1}$, Mirnawati ${ }^{2}$, Indra Akbar ${ }^{3}$ \\ ${ }^{1,2,3)}$ Program Studi Administrasi Perkantoran, Politeknik Kutaraja, Banda Aceh \\ e-mail: zahriatulaini@poltekkutaraja.ac.id
}

\begin{abstract}
Abstrak
Kegiatan Pengabdian kepada Masyarakat (PkM) dengan melaksanakan pelatihan bagi guru dan tenaga kependidikan di Dayah Darul Ihsan Tgk H. Hasan Krueng Kalee Aceh Besar secara kualitatif telah berhasil meningkatkan wawasan dan pengetahuan yang lebih luas dan mendalam dari sebelumnya dalam mengelola arsip di lingkungan lembaga pendidikan tersebut. Dengan menggunakan metode Pembelajaran Orang Dewasa (POD) sebagai teknik pelatihan yang dipadukan dengan model pembelajaran akfif dan interaktif membuat suasana belajar menjadi lebih menarik dan menyenangkan. Dari hasil evaluasi paska pelatihan yang dilakukan oleh tim instruktur PkM secara menemukan bahwa terjadi perubahan secara kognitif mencapai 85 persen secara ratarata. Inilah pentingnya kegiatan PkM dilakukan sehingga ilmu pengetahuan bermanfaat secara nyata untuk kemajuan masyarakat.
\end{abstract}

Kata Kunci: Pengabdian kepada Masyarakat, Pesantren, Kearsipan, Dokumen

\begin{abstract}
Community Service Activities (PkM) by conducting training for teachers and education personnel at Dayah Darul Ihsan Tgk H. Hasan Krueng Kalee Aceh Besar have qualitatively succeeded in increasing broader and deeper insights and knowledge than before in managing archives within the educational institution. . By using the Adult Learning (POD) method as a training technique combined with active and interactive learning models, the learning atmosphere becomes more interesting and fun. From the results of the post-training evaluation conducted by the PkM instructor team, it was found that there was a cognitive change that reached 85 percent on average. This is the importance of PkM activities to be carried out so that science is actually useful for the progress of society.
\end{abstract}

Keywords: Community Service, Islamic Boarding Schools, Archives, Documents

\section{PENDAHULUAN}

Menurut Undang-undang Republik Indonesia Nomor 20 Tahun 2003 tentang Sistem Pendidikan Nasional pada pasal (1) Ketentuan umum yang dimaksud dengan pendidikan adalah usaha sadar dan terencana untuk mewujudkan suasana belajar dan proses pembelajaran agar peserta didik secara aktif mengembangkan potensi dirinya untuk memiliki kekuatan spiritual keagamaan, pengendalian diri, kepribadian, kecerdasan, akhlak mulia, serta keterampilan yang diperlukan dirinya, masyarakat, bangsa, dan Negara. (https://sipuu.setkab.go.id ). Makna pendidikan tersebut secara ekplisit tercantum dalam undang-undang yang kemudian disebut sebagai tujuan pendidikan nasional.

Sedangkan tenaga kependidikan adalah anggota masyarakat yang mengabdikan diri dan diangkat untuk menunjang penyelenggaraan pendidikan. Keberadaan tenaga kependidkan turut mempengaruhi jalannya proses pembelajaran yang berlangsung pada sebuah lembaga pendidikan baik formal maupun informal. Selain memiliki tenaga pendidik yakni guru, dosen, ustadz/ah, dan pengajar yang berkompeten dan profesional, ketersediaan tenaga kependidikan yang mampu melayani segenap murid, siswa, atau santri dan menata operasionalisasi sistem administrasi yang baik juga memberikan kontribusi positif bagi keberlangsungan system pendidikan secara menyeluruh. 
Lembaga pendidikan yang dikenal di Indonesia bukan hanya sekolah namun ada juga pesantren. Pesantren merupakan lembaga pendidikan tertua di Indonesia. Sistem pendidikan ini dimulai sejak munculnya masyarakat Islam di nusantara yaitu pada abad ke-13. (Yanti, S.H. 2019). Dunia pesantren memiliki kultur dan metode belajar sendiri yang khas dan unik. Di lembaga ini peserta didik yang disebut santri diajarkan berbagai pengetahuan tentang agama Islam, adab, dan moralitas yang baik sebagai bekal untuk hidup dan bergaul dalam masyarakat.

Sebagai model pendidikan tertua pesantren sudah memasuki usia mapan dan cenderung tidak berkembang dalam hal inovasi. Pesantren mengalami stagnan pada tataran penerapan teknologi informasi bahkan pada sebagian para pendidik dan penyelenggara kependidikan di pesantren tidak memandang modernisasi sebagai potensi positif untuk mengembangkan pesantren. Akibatnya sistem pendidikan pesantren mengalami kebuntuan dalam menerapkan manajemen adminitrasi salah satunya adalah kearsipan.

Manajemen kearsipan sangat dibutuhkan pada organisasi. Pesantren dapat digolongkan sebagai organisasi dalam hal ini adalah organisasi nirlaba yang melayani publik. Arsip mempunyai nilai dan peran penting dalam organisasi karena arsip merupakan bahan bukti resmi mengenai penyelenggaraan administrasi intistusi tersebut. Oleh karena itu sangat ironi bila di zaman modern ini masih terdapat sejumlah pesantren di Aceh yang belum mampu melaksanakan manajemen kearsipan atau administrasi di secara baik dan memenuhi standar perkantoran.

Padahal pesantren sebagai sebuah lembaga pendidikan umat Islam sejatinya menjadi modal dan model dalam memberikan layanan dan informasi bagi seluruh pihak baik internal maupun ekternal. Sehingga pesantren dikenal sebagai lembaga pendidikan yang bermutu dan adaptif dalam merespon kebutuhan umat. Namun demikian keberadaan pesantren di Indonesia dan Aceh khususnya sangat membantu pemerintah dalam mengembangkan sumber daya manusia yang siap berkiprah di tengah-tengah masyarakat. Bahkan alumni pesantren mampu berkiprah dalam pembangunan bangsa dan Negara.

Penelitian sebelumnya Yanti S.H. (2019) dengan judul Manajemen Kearsipan Pada Pondok Pesantren Modern Babun Najah Banda Aceh menunjukkan bahwa manajemen kearsipan pada Pondok Pesantren Modern Babun Najah Banda Aceh meliputi pertama, proses perencanaan dilaksanakan ketika rapat (1) merencanakan ketertiban arsip; (2) kelengkapan sarana prasarana; dan (3) kecepatan dalam menemukan arsip. Kedua, proses pengorganisasian dilakukan sesuai dengan kondisi dan situasi. Ketiga, proses pelaksanaan arsip (1) sistem penyimpanan arsip menggunakan abjad dan tanggal atau tahun; (2) peminjaman arsip dilakukan dengan cara pengambilan arsip, penyerahan arsip, pengkopian arsip dan pengembalian arsip; (3) pemeliharaan arsip dilakukan dengan membersihkan ruangan arsip; dan (4) penyusutan arsip dilakukan dengan pemindahan arsip keruangan yang lain. Keempat, proses pengawasan arsip dilakukan minimal 2 bulan atau maksimal persemester. Kendala manajemen kearsipan, pertama, kurangnya pemahaman staf tata usaha dalam manajemen kearsipan. Kedua, terbatasnya sarana prasarana manajemen kearsipan. Solusi terhadap kendala manajemen kearsipan, pertama, mengikutsertakan staf tata usaha pada kegiatan pelatihan pengembangan bidang kearsipan. Kedua, petugas arsip melakukan penyeleksian arsip berdasarkan klasifikasi arsip yang penting dengan arsip yang kurang penting untuk diletakkan di dalam lemari dan dipindahkan keruangan yang lain.

Namun hasil penelitian tersebut belum dapat digeneralisasikan kepada seluruh pesantren atau dayah yang ada di Aceh mengingat setiap dayah memiliki karakteristik dan tata nilai yang berbeda dalam melaksanakan kegiatan operasional pendidikan dan layanan kepada stakeholder nya. Oleh sebab itu kegiatan PkM ini ditujukan pada dayah Darul Ihasan sebagai sasaran dan mempelajari lebih dalam permasalahan yang dihadapi untuk mendapatkan solusinya.

Guna meningkatkan kemampuan penyelenggara pendidikan di Dayah Darul Ihsan H. Hasan Krueng Kalee Aceh Besar terutama para guru dan tenaga kependidikan dalam mengelola arsip dan seluruh dokumen lainnya yang bernilai otentik bagi sistem mutu manajemen serta mampu mengolah menjadi informasi yang berguna bagi pihak berkepentingan, maka perlu dilakukan kegiatan capacity building dalam bentuk pelatihan bagi guru dan tenaga kependidikan. Kegiatan ini penting untuk dilakukan karena adanya kebutuhan yang mendesak agar Dayah Darul Ihsan H. Hasan Krueng Kalee dapat semakin eksis dan berkembang serta tidak tertinggal dengan pesantrenpesantren lain di nusantara. 
Kegiatan pelatihan peningkatan kapasitas bagi guru dan tenaga kependidikan di Dayah Darul Ihsan dilaksanakan oleh Tim Pengabdian kepada Masyarakat (PkM) Program Studi Administrasi Perkantoran Politeknik Kutaraja sebagai bagian dari tridharma perguruan tinggi yang diamanahkan oleh Undang-undang Republik Indonesia Nomor 12 Tahun 2012 tentang Perguruan Tinggi yang menyatakan bahwa pendidikan tinggi adalah bagian dari sistem pendidikan nasional yang memiliki peran strategis dalam mencerdaskan kehidupan bangsa serta memajukan ilmu pengetahuan dan teknologi. Oleh karena diwajibkan bagi perguruan tinggi untuk melaksanakan kegiatan pengabdian kepada masyarakat sebagai sarana untuk mengembangkan ilmu pengetahuan dan penerapannya dalam kehidupan masyarakat.

\section{METODE}

Kegiatan Pengabdian kepada Masyarakat $(\mathrm{PkM})$ ini dilaksanakan guna menyelesaikan permasalahan yang dihadapi oleh guru dan tenaga kependidikan di Dayah Darul Ihsan dalam mengelola arsip dan dokumen outentik lainnya di lingkungan pesantren agar lebih tertib, teratur, dan termonitor dengan baik. Bentuk kegiatan yang dipilih adalah pelatihan dengan metode Pembelajaran Orang Dewasa (POD) yang diikuti oleh 36 peserta yang terdiri dari guru tetap dan tenaga kependidikan. Pelatihan ini berlangsung selama 3 hari sejak 23-27 Januari 2019. Metode POD dalam pelatihan ini bertumpu pada model belajar proaktif, mandiri, dan partisipatif. Dimana peserta diharapkan dengan inisiatif tinggi untuk mengikuti setiap materi, presentasi, dan bimbingan intstruktur.

Menurut (Asmin, 2011), dalam pendidikan atau pembelajaran orang dewasa peserta bukan lagi sebagai objek sosialisasi yang seolah-olah dibentuk dan dipengaruhi untuk menyesuaikan dirinya dengan keinginan meegang otoritas atas dirinya sendiri, akan tetapi tujuan kegiatan belajar atau pendidikan orang dewasa tentunya lebih mengarah kepada pencapaian pemantapan identitas dirinya untuk menjadi dirinya sendiri. Dengan demikian peserta pelatihan tidak merasa sedang digurui dan akhirnya antipati mengikuti kegiatan.

Adapun hasil yang diharapkan dari kegiatan PkM ini adalah bertambahnya wawasan dan pengetahuan para guru dan tenaga kependidikan di Dayah Darul Ihsan terhadap kearsipan, meningkatnya kesadaran untuk melaksanakan manajemen kearsipan di lingkungan dayah dan organisasi sekolah, dan terwujudnya pengelolaan arsip yang sistematis.

Model pelaksanaan kegiatan pelatihan metode POD sebagai alur piker seperti dijelaskan pada skema berikut ini:

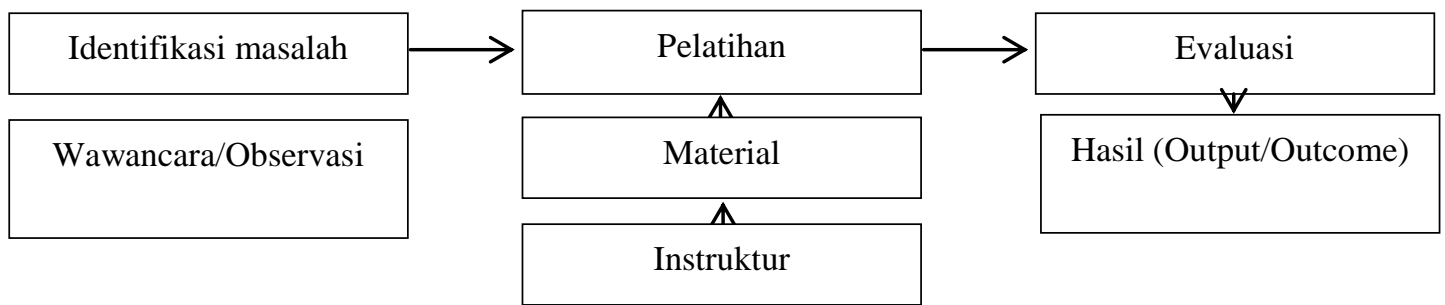

Gambar 1. Logika Berpikir Pelatihan (sumber: Yusra and Hamdani, 2010) dimodifikasi

\section{HASIL DAN PEMBAHASAN}

Arsip memiliki peran penting dalam administrasi modern. Arsip tidak hanya diperlukan pada organisasi besar bahkan setiap organisasi saat ini membutuhkan pengelolaan arsip secara sistematis dan terdokumentasi dengan baik. Di pesantren Dayah Darul Ihsan pengelolaan arsip dalam beberapa tahun belakang ini belum dilaksanakan dengan prinsip manajemen arsip yang ideal. Pelaksanaan tata kelola arsip di lingkungan dayah tersebut masih bersifat sederhana dan belum open access (bersifat terbuka). Pelatihan ini dirancang untuk memberikan pengetahuan yang lebih mendasar dan komprehensif bagi peserta dalam memahami manajemen kearsipan. 
Menurut Kamus Besar Bahasa Indonesia (KBBI, 2016) kearsipan berasal dari kata arsip yang berarti dokumen tertulis (surat, akta, dan sebagainya), lisan (pidato, ceramah, dan sebagainya) atau gambar (foto, film, dan sebagainya) dari waktu yang lampau, disimpan dalam media tertulis (kertas), elektronik (pita kaset, pita video, disket computer, dan lain sebagainya), biasanya dikeluarkan oleh instansi resmi disimpan dan dipelihara di tempat khusus untuk referensi.

Keberadaan dayah sebagai salah satu sistem pendidikan formal di Aceh telah ikut berkontribusi bagi kemajuan sumber daya manusia. Lembaga pendidikan ini telah banyak memberikan manfaat bagi pembangunan daerah dan nasional terutama dalam sektor agama Islam. Berdasarkan data yang dikeluarkan oleh Badan Dayah Aceh tahun 2020 jumlah pesantren atau dayah sebanyak 1.136 buah. Data tersebut merupakan yang telah terdaftar di Badan Dayah Aceh sedangkan secara keseluruhan mencapai 2.000 buah yang tersebar di 23 kabupaten/kota.

Menurut (Marzuki, 2011), Dayah (bahasa Aceh) adalah nama lembaga yang dikenal dengan sebutan pesantren di Jawa atau surau di Padang atau pondok di Thailand. Kata Dayah ini berasal dari bahasa Arab "zawiyah". Istilah zawiyah, secara literal bermakna sudut, yang diyakini oleh masyarakat Aceh pertama sekali digunakan sudut mesjid Medinah ketika Nabi memberi pelajaran kepada para shahabat di awal Islam 2 orang-orang ini, sahabat Nabi kemudian menyebarkan Islam ke tempat- tempat lain.

Minat masyarakat Aceh untuk menyekolahkan anak-anak nya di Dayah saat ini terjadi peningkatan pesat. Sehingga setiap tahun ajaran baru ketika masa penerimaan santri baru (sebutan siswa di Dayah) dibuka jumlah yang mendaftar sangat banyak hingga 2 kali lipat dari kuota yang diterima. Begitu pula halnya di pesantren atau Dayah Darul Ihsan. Oleh karena itu pihak manajemen dayah harus mampu mengelola seluruh dokumen baik yang masuk maupun yang keluar terkait dengan fungsinya dalam menyelenggarakan pendidikan.

Hasil pelatihan kearsipan telah menunjukkan perubahan cara pandang para guru dan tenaga kependidikan terhadap pentingnya pengelolaan dokumen dan manajemen kearsipan di lingkungan sekolah dan dayah. Perubahan paradigma tersebut terjadi setelah para peserta mengikuti program singkat ini selama 2 hari yang diukur dengan instrumen evaluasi. Para peserta diberikan materi sebagai bahan pelajaran dan sumber belajar dari media internet dengan topik-topik yang terkait langsung dengan manajemen kearsiapan. Peserta diminta untuk mempelajari bahan ajar tersebut selama 30 menit dalam setiap sesi kelas, kemudian dilanjutkan dengan latihan/praktik dengan metode pembelajaran role play (bermain peran) untuk meningkatkan pemahaman.

Sementara instruktur bertindak sebagai fasilitator untuk menjembatani proses pembelajaran dan membawa peserta pada tujuan yang dicapai dalam setiap indikator output/outcome. Untuk penggunaan alat peraga tim pelatih sudah menyiapkan bahan-bahan yang diperlukan seperti box file, book filling, buku agenda, laptop, map folio, dan prasarana lainnya. Dengan mengoptimalkan penggunaan alat bantu/alat peraga belajar, para peserta dapat melakukan simulasi secara langsung dalam menangani tahap demi tahap kegiatan dalam manajemen kearsipan. Dengan teknik seperti ini terbukti bahwa tingkat pengetahuan dan keterampilan peserta pelatihan meningkat sangat signifikan.

Dari hasil penelitian dalam kegiatan Pengabdian kepada Masyarakat (PkM) ini ditemukan bahwa penerapan administrasi di Dayah Darul Ihsan masih perlu dibenahi secara parsial. Penataan harus lebih terprogram dan terstruktur sehingga tata kelola kearsipan akan semakin baik dan terstandarisasi. Kemudian perlu dilakukan perencanaan pengelolaan arsip setiap tahun agar file, warkat maupun dokumen yang sudah dikoleksi dapat dijaga dan dirawat demi keamanan dan bahkan terjamin kerahasiaannya dari potensi kerusakan dan kebocoran informasi.

\section{SIMPULAN}

Hasil kegiatan PkM dan penelitian ini dapat disimpulkan bahwa pengelolaan kearsipan di pesantren atau dayah yang mejalankan fungsi sebagai organisasi layanan publik masih harus terus diberikan dukungan oleh semua pihak terutama perguruan tinggi untuk meningkatkan kapasitas sumber daya manusia. Melalui program pengabdian kepada masyarakat yang dilaksanakan oleh tim PkM Program Studi Administrasi Perkantoran, Politeknik Kutaraja, Banda Aceh telah memberikan motivasi bagi guru dan tenaga kependidikan di Dayah Darul Ihsan untuk belajar lebih 
giat lagi dalam mengelola arsip siswa, dokumen sekolah, data dayah, dan warkat otentik lainnya sebagaimana diatur dalam peraturan kearsipan.

\section{SARAN}

Kegiatan PkM pelatihan Pengelolaan Kearsipan ini sangat baik untuk dilakukan oleh perguruan tinggi kepada masyarakat terutama organisasi yang berhadapan langsung dengan pelayanan public dalam hal dokumen, surat menyurat, dan aspek administrasi. Kedepan diharapkan pemerintah juga aktif memberikan penyuluhan, pelatihan, dan bantuan pendampingan agar dayah atau pesantren mampu menerapkan fungsi-fungsi manajemen kearsipan di lingkungan nya. Sehingga profesionalisme penyelenggara pelayanan public semakin baik dan pada akhirnya menghasilkan pelayanan prima (service exellence) bagi masyarakat.

\section{DAFTAR PUSTAKA}

Asmin. (2011). Konsep Dan Metode Pembelajaran Untuk Orang Dewasa (Andragogi). Jurnal Unimed Medan. https://doi.org/10.1016/j.jog.2012.02.009

Yanti, S. H. (2019). Manajemen Kearsipan Pada Pondok Pesantren Modern Babun Najah Banda Aceh (Doctoral dissertation, UIN Ar-Raniry Banda Aceh).

Harmaini, Pengelolaan Kearsipan di MTsS Pondok Pesantren Ashhabul Yamin Bakongan. Juli 2017. Diakses pada tanggal 13 Mei 2018 dari situs: http://repository.arraniry.ac.id/1500/1/HARMAINI.pdfn.

KBBI. (2016). Kamus Besar Bahasa Indonesia ( KBBI ). In Kementerian Pendidikan dan Budaya.

Marzuki, M. (2011). SEJARAH DAN PERUBAHAN PESANTREN DI ACEH. Millah. https://doi.org/10.20885/millah.vol11.iss1.art11

YUSRA, Y., \& HAMDANI, H. (2019). Penggunaan model pembelajaran picture and picture untuk meningkatkan keterampilan siswa dalam Berbicara Bahasa Inggris di SMP Negeri 2 Banda Aceh. JEPS (Jurnal Ekonomi, Pendidikan, dan Sains), 3(1), 1-6.

https://www.ajnn.net/news/jumlah-dayah-di-aceh-mencapai-2-ribu-terdaftar-hanya-1-136dayah/index.html

https://sipuu.setkab.go.id/PUUdoc/7308/UU0202003.htm

https://sipuu.setkab.go.id ). 